Institute of $\mathbf{F}_{\text {ood and }} \mathbf{A}_{\text {gricultural }} \mathbf{S}_{\text {ciences }}$

\title{
Manual de los Reglamentos del Agua de Florida: Distritos de Manejo del Agua ${ }^{1}$
}

\author{
Michael T. Olexa, Laura Minton, Dulcy Miller, y Sarah Corbett ${ }^{2}$
}

\section{Agradecimientos}

Los autores agradecen a Richard Budell de la Oficina de Política del Agua Agrícola del Departamento de Agricultura y Servicios al Consumidor de Florida. Los autores también agradecen a David H. Hammonds, Consultor del Programa de Salud Ambiental, Oficina de Programas de Aguas de Drenaje en el Sitio, del Departamento de Salud de Florida, y a Edward A. Bettinger, Consultor del Programa de Salud Ambiental, Oficina de Programas de Agua del Departamento de Salud de Florida.

\section{Sinopsis}

Excepto los Distritos de Manejo del Agua del Sur de Florida y el del Suroeste de Florida, los cuales fueron creados legislativamente para dirigir los problemas de inundaciones y escasez de agua, los Distritos de Manejo de Agua (DMA) fueron creados como agencias publicas conforme el Capitulo 373, de los Estatutos de Florida, conocidos como el Acta de Recursos del Agua de Florida de 1972. Los DMAs juegan un rol muy importante en la regulación del control y uso del agua del agricultor.

La responsabilidades de los DMAs incluyen:

- manejo de agua y recursos relacionados a la tierra vía promoción de conservación.

1. Este es el documento EDIS FE073, una publicación del Department of Food and Resource Economics, Florida Cooperative Extension Service, Institute of Food and Agricultural Sciences, University of Florida, Gainesville, FL. Publicada Noviembre 2002. Por favor visite la página electrónica EDIS en http://edis.ifas.ufl.edu.

2. Michael T. Olexa, es profesor del Department of Food and Resource Economics, Florida Cooperative Extension Service, Institute of Food and Agricultural Sciences, University of Florida, Gainesville, FL; y miembro de Florida Bar; Presidente de Agricultural Law Committee of The Florida Bar; y Director del Agricultural Law Center. Laura Minton, Dulcy Miller, y Sarah Corbett son estudiantes graduadas de Levin College of Law, University of Florida, Gainesville, FL. Filiberto Reyes-Villanueva fue el traductor de la versión en ingles al español.

Esta publicación esta diseñada para proporcionar información precisa, actualizada y autorizada sobre esta material. Sin embargo, ya que las leyes, reglas administrativas y decisiones de la corte, sobre las cuales están basados, están sujetas a revisión constante; algunas partes de esta publicación podrían ser obsoletas en cualquier momento. Esta publicación es distribuida bajo el entendimiento que los autores no están involucrados en ninguna representación legal u otros servicios profesionales, y que la información contenida aquí no debe ser considerada como un substituto de una asesoria legal. Esta publicación no esta completa en proporcionar toda la información para lograr el cumplimiento de las leyes y reglamentos que gobiernan la protección del agua. Por estas razones, el uso de estos manuales por cualquier persona constituye un acuerdo para mantener libre de daño a los autores, al Florida Cooperative Extension Service, al Institute of Food and Agricultural Sciences, y a la University of Florida por cualquier demanda por responsabilidad de daños, o gastos en que pueda incurrir cualquier persona, como un resultado de hacer referencia o confianza sobre la información contenida en esta publicación. Esta publicación fue apoyada financieramente por el Florida Department of Agriculture and Consumer Services.

El Instituto de Alimentos y Ciencias Agrícolas es Un empleador que opera bajo Acción Afirmativa y provee Oportunidades Igualitarias, dedicado a promocionar la investigación, a información educativa y otros servicios, únicamente a los individuos e instituciones que operan baj discriminación sin considerar color, raza, sexo, edad, incapacidad u origen. Para más información sobre como obtener otras publicaciones de la extensión, comuníquese con la oficina de Servicio de Extensión de su condado. Servicio de Extensión de la Florida / Instituto de Alimentos y Ciencias Agrícolas / Universidad de la Florida / Christine Taylor Waddill, Decana. 
- utilización apropiada de los recursos del agua de superficie y subterránea.

- regulación de las presas, estanques, reservorios y otras estructuras que alteren el movimiento de las aguas superficiales.

- combatir el daño por las inundaciones, erosión del suelo y drenaje excesivo.

- ayudar a los gobiernos locales en el desarrollo amplio de los planes de manejo del agua, particularmente proporcionando datos sobre los recursos del agua.(los DMAs están autorizados para ejecutar diferentes investigaciones de campo, y encargarse de trabajos para el almacén benéfico del agua).

- mantenimiento de ríos navegables y puertos y promocionar la salud, seguridad y bienestar general de la población del estado (directamente anexo a esta consideración del bienestar general, esta el poder para implementar planes de emergencia para la para la escasez de agua).

- participación en el programa de control de inundaciones y la recuperación, conservación y protección de las tierras por exceso o deficiencias de agua.

- mantener el manejo del agua y usar las instalaciones para determinar los niveles de agua que deben ser mantenidos en los cuerpos de agua del distrito (los distritos pueden establecer flujos mínimos para sus trabajos y cursos de agua debajo de los cuales, retiros adicionales serian significativamente dañinos para los recursos de agua o la ecología, y para los mínimos niveles de aguas superficiales y subterráneas).

\section{¿Cuál es la Estructura de los DMAs?}

Cada distrito es conducido por una junta de gobierno consistente de nueve miembros, excepto el distrito del Suroeste de Florida, el cual tiene once. Los miembros sirven en periodos de cuatro años y están nombrados por el gobernador y confirmados por el estado. La junta de gobierno establece políticas que harán mas efectivos los poderes de los distritos. Generalmente, un director ejecutivo es responsable por la operación del distrito, incluyendo la implementación de las políticas y reglas. Típicamente, cada distrito esta dividido en departamentos que manejan los diferentes programas de permisos. Cada distrito esta completamente equipado para llevar a cabo sus propias inspecciones, análisis y estudios de impacto.

Un distrito, el Distrito de Manejo de Agua del Suroeste de Florida, esta además dividido en cuencas divisorias las cuales son supervisadas por las juntas de cuencas. La junta debe consistir de al menos tres personas, uno de cada condado miembro. Los miembros de la junta tienen autoridad para preparar planes de ingeniería para el desarrollo de los recursos del agua, desarrollar planes para el uso secundario del agua, proponer un presupuesto anual, aprobar planes de construcción para trabajos del distrito y planear y proporcionar asistencia a las autoridades del servicio de agua.

\section{¿Para qué dan Permisos los DMAs?}

Los poderes del consejo de gobierno de un DMA incluye administrar los programas permitidos del Capitulo 373, de los Estatutos de Florida. Así, los DMAs son responsables por permitir:

- pozos.

- manejo y almacén de aguas superficiales.

- usos del consumo del agua.

\section{¿Qué es el Plan de la Calidad del Agua del Estado?}

El Departamento de Protección Ambiental (DPA) ha sido dirigido para preparar el plan de uso del agua del estado y para fomentar convenios ínter agencias para lograr el Plan de la Calidad del Agua del Estado. El plan del uso del agua esta desarrollado por el DPA a través de consultas con agencias federales, estatales, y locales y particularmente los DMAs. El plan incluye todas las aguas en el estado. Su principal propósito es reconocer diferentes intereses que compiten por los derechos del uso del agua y asignar estos derechos mientras mantiene un control razonable de la calidad y cantidad del agua. 
Así promueve los objetivos de protección del medio ambiente, drenaje apropiado, control de inundaciones y almacén del agua.

Además, el Plan de Calidad del Agua del Estado enlaza los propósitos del Acta de Recursos del Agua de Florida, con los objetivos del Acta para el Control de la Contaminación del Agua y Aire de Florida, Capitulo 403, de los Estatutos de Florida, a través de sus estándares de la calidad del agua. El resultado neto es que el DPA mantiene responsabilidad central para la colección de datos científicos, e información concerniente a los recursos del agua, con las responsabilidades primarias de emisión de permisos asignados a los DMAs.

El DPA también mantiene poder regulatorio directo sobre lo siguiente:

- descargas de fuentes de punto.

- dragado y relleno.

- descargas de aguas del subsuelo.

- lo concerniente a desechos sólidos y peligrosos.

- filtración en tanques de almacén subterráneos.

En contraste, los DMAs son altamente responsables por emitir permisos para los diferentes tipos de usos del agua, y los cuerpos gubernamentales están a cargo de la asignación y control de los recursos del agua para los cuales hay muchos intereses compitiendo.

\section{¿Qué Impuestos Pueden Aplicar los DMAs?}

Lo mas indicativo de sus amplios poderes es la habilidad de los DMAs para aplicar impuestos ad valorem (impuestos sobre la propiedad). Los impuestos Ad valorem son aplicados en base al valor de la propiedad en cuestión. La Constitución de Florida establece una tasa tope para impuestos, y estas tasas están adicionalmente limitadas por los estatutos.
Cada DMA es diferente. La autoridad para aplicar impuestos es ejecutada por los DMAs con los consejos de cuencas. Los consejos de cuencas pueden solicitar que los impuestos sean aplicados, pero no pueden imponer ser aplicados por ellos mismos. Como con otras disposiciones de impuestos del gobierno, las fallas por pagar pueden resultar en un gravamen sobre la propiedad bajo impuesto, incluyendo la casa habitación, y finalmente poner un rotulo de confiscación por incumplimiento de impuestos en el estado. 